\title{
How to do it: Thoracoscopic left ventricular assist device implantation using robot assistance
}

\author{
Zain Khalpey, MD, PhD, MRCS (Eng), Nicole Sydow, MD, Marvin J. Slepian, MD, and
}

Robert Poston, MD, Tucson, Ariz

Left ventricular assist devices (LVADs) improve quality of life and reduce mortality of patients with heart failure. ${ }^{1}$ Although LVAD outcomes improve, unavoidable consequences of implantation remain. Given the likeliness of prior cardiac surgery, LVAD candidates for a "bridge

From the Departments of Cardiothoracic Surgery and Cardiology, University of Arizona, Tucson, Ariz.

Disclosures: Dr Poston is supported by grants from Intuitive Surgical Inc and the National Institutes of Health (RO1 HL084080). All other authors have nothing to disclose with regard to commercial support.

Received for publication Oct 2, 2013; revisions received Nov 13, 2013; accepted for publication Nov 22, 2013.

Address for reprints: Zain Khalpey, MD, PhD, MRCS (Eng), 1501 N. Campbell Ave, Tucson, AZ 85724 (E-mail: zkhalpey@surgery.arizona.edu).

J Thorac Cardiovasc Surg 2014;147:1423-5

$0022-5223 / \$ 36.00$

Copyright (C) 2014 by The American Association for Thoracic Surgery

http://dx.doi.org/10.1016/j.jtcvs.2013.11.032 to transplant" raise concerns regarding the number of redo sternotomies. Each sternotomy places patients at greater risk for mortality, morbidity, and resource use (eg, blood transfusions and length of stay). ${ }^{2}$ These increased risks are attributed to patients' heart failure associated with sternum-adherent dilated right ventricles (RVs). ${ }^{3}$ Direct cardiac dissection of adhesions via sternotomy can be poorly tolerated and trigger postoperative RV failure by prolonged cardiopulmonary bypass (CPB) time, bleeding, excessive transfusions, and inflammation. An alternative to redo sternotomy is a robotic endoscopic approach via thoracic chest ports. This indirect approach to the retrosternal space improves adhesion visualization, allowing more precise dissection. Reports of robotic use for redo or high-risk cases led us to assess robotic utility to reduce the invasiveness and morbidity in patients undergoing LVAD implantation.

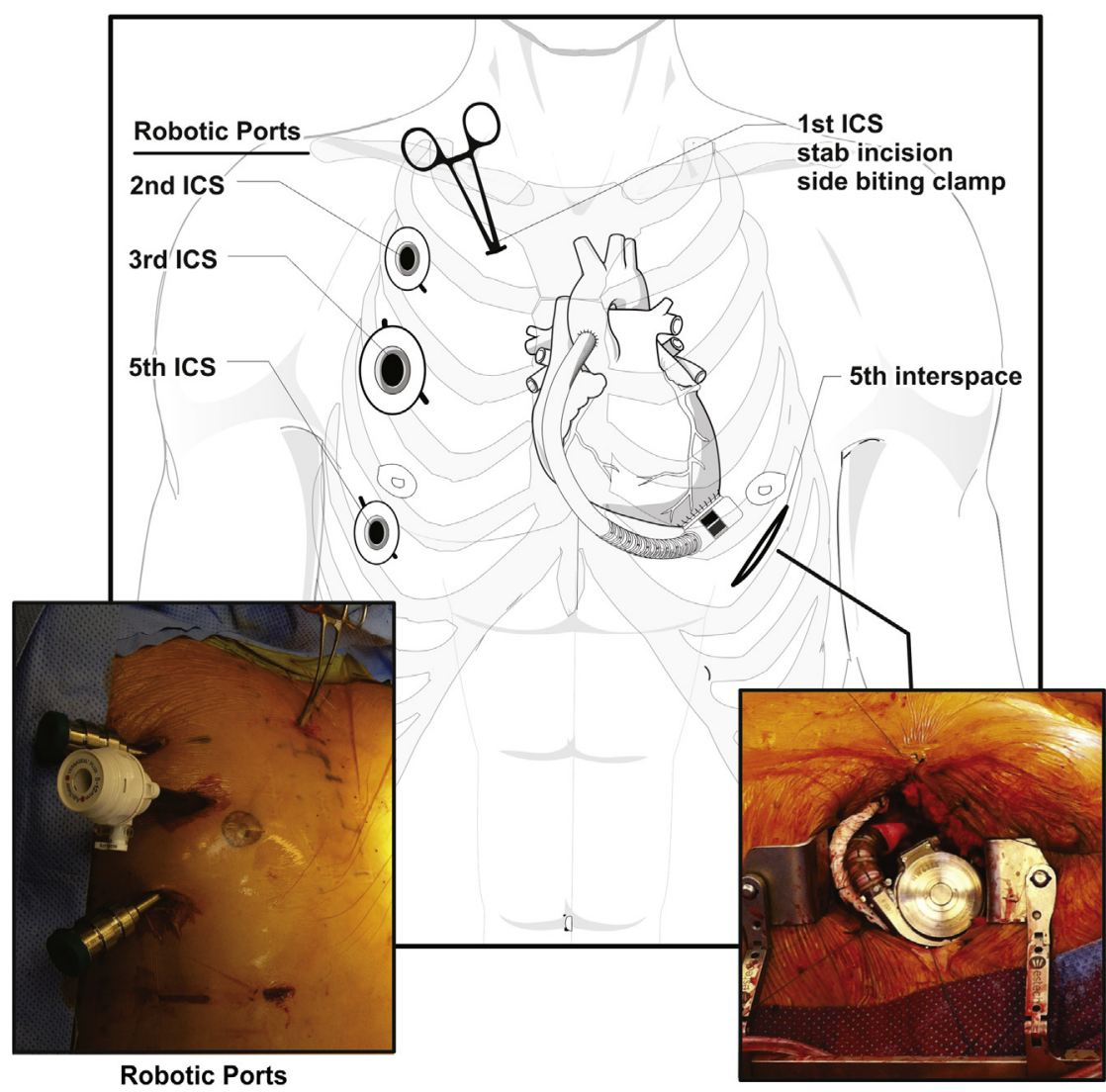

FIGURE 1. Placement of robotic port sites in intercostal spaces (ICS) and incisions with depiction of the HVAD (HeartWare International Inc, Framingham, Mass) after implantation. 

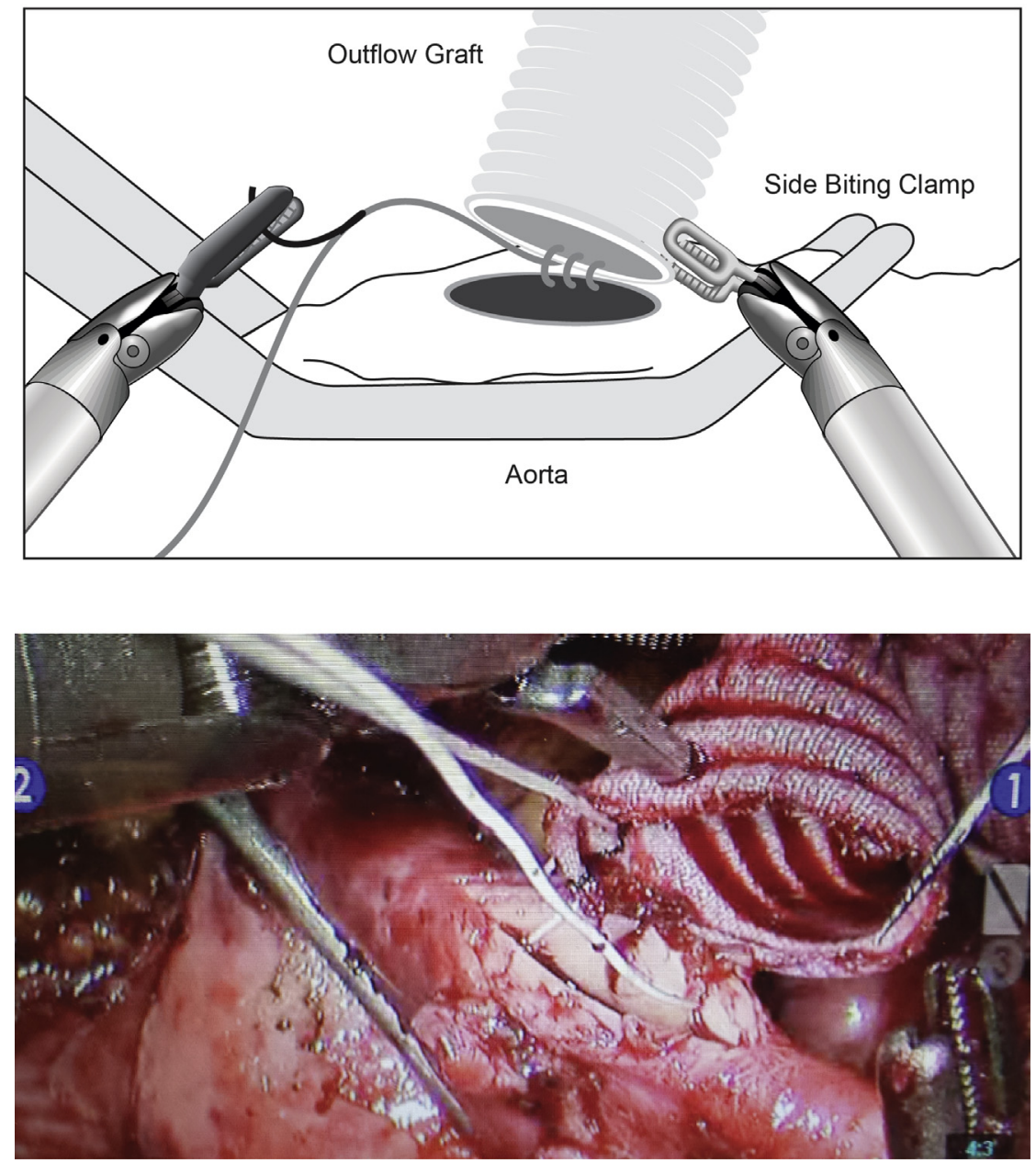

FIGURE 2. Total endoscopic anastomosis of outflow graft to aorta using the da Vinci robot (Intuitive Surgictal, Inc, Sunnyvale, Calif).

\section{CLINICAL SUMMARY}

A 49-year-old man awaiting transplant with dilated cardiomyopathy was evaluated for LVAD implantation after a decompensated period of heart failure. A miniaturized device (HVAD; HeartWare International Inc, Framingham, Mass) was implanted into the left ventricular apex via a left mini-thoracotomy incision. The da Vinci robot (Intuitive Surgical, Inc, Sunnyvale, Calif) was used to create the anastomosis of the outflow graft with the ascending aorta. With the patient supine, the right femoral vessels were cannulated for $\mathrm{CPB}$. A small left anterior thoracotomy exposed the cardiac apex, localized via preoperative chest computed tomography imaging, and the inflow sewing ring was sutured into place. The pump was positioned within the left thorax, and the drive line was tunneled subcutaneously over the lower left ribs.

With the right lung isolated, 3 small robotic ports were placed in the right chest via the second (left robotic arm), third (camera and working port), and fifth (right robotic arm) intercostal spaces in the anterior axillary line
(Figure 1). Robotic assistance was used to pass the outflow graft through a mediastinal tunnel created anterior to the RV into the right chest for anastomosis with the aorta (Figure 2). Direct visualization allowed for accurate measurement and placement along the diaphragm (conventional placement of outflow) and prevented kinking.

A side-biting clamp was placed onto the ascending aorta via a stab incision in the first intercostal space, right of midline with direct visualization to avoid injuring the right internal thoracic artery. CPB was initiated after appropriate activated clotting time-guided heparinization; an apical core was removed from the left ventricle, and the HVAD was secured into position. The outflow cannula was anastomosed to the aorta with 5.0 running polytetrafluoroethylene (Gore-Tex; WL Gore \& Associates Inc, Flagstaff, Ariz) suture performed initially by hand in the first few patients and then totally endoscopically using robotic instruments with and without a $2-\mathrm{cm}$ right anterior thoracotomy. Once the device was placed, flow through the device was initiated, and an angiocatheter was placed into the outflow graft to de-air 
through the third intercostal space. The device was covered with a polytetrafluoroethylene (Gore-Tex) mesh to minimize lung adhesions.

For 7 cases, bypass times ranged from 68 to 136 minutes. Intraoperative blood product use ranged from 0 to 3 units of red blood cells, 2 to 3 units of fresh frozen plasma, and 1 to 2 pooled platelet units. Preoperatively, all patients had at least moderate RV dysfunction determined by cardiac magnetic resonance imaging (RV ejection fraction range, 20\%$35 \%$ ). Yet, postoperative RV failure did not develop in any of the patients. Four patients were extubated between 12 and 24 hours after surgery. The other 3 patients were extubated on postoperative days 2,5 , and 7 .

\section{DISCUSSION}

As LVAD support for patients with heart failure becomes increasingly popular, concern for redo sternotomies increases. ${ }^{4}$ Further, reoperative sternotomy at the time of subsequent heart transplantation has been associated with decreased short- and long-term survival. To avoid redo sternotomy, new methods of LVAD implantation must be explored, particularly as new-generation devices become smaller and more conducive to minimally invasive implantation. Our approach improves on existing less-invasive approaches for LVAD implantation because robotic technology provides optimal visualization for RV dissection and reduced risk of kinking the outflow graft. ${ }^{5}$ Performing the anastomosis of the graft to the ascending aorta through right chest ports further decreases mediastinal dissection. This may improve outcomes in these patients at the time of transplantation. Furthermore, the robotic ports discussed are suitable for concomitant procedures usually performed through the right chest.

\section{CONCLUSIONS}

Refinements in surgical technique, team development and training methods, and patient selection and management will enable robotic technology to play an important role in LVAD implantation.

The authors thank Katherine Stavoe and Kitsie Penick for assistance with article preparation and Rita Ellsworth for developing the figures.

\section{References}

1. Rose EA, Gelijns AC, Moskowitz AJ, Heitjan DF, Stevenson LW, Dembitsky W, et al. Randomized Evaluation of Mechanical Assistance for the Treatment of Congestive Heart Failure (REMATCH) Study Group. Long-term use of a left ventricular assist device for end-stage heart failure. $N$ Engl J Med. 2001;345: $1435-43$.

2. George TJ, Beaty CA, Ewald GA, Russell SD, Shah AS, Conte JV, et al Reoperative sternotomy is associated with increased mortality after heart transplantation. Ann Thorac Surg. 2012;94:2025-32.

3. Park CB, Suri RM, Burkhart HM, Greason KL, Dearani JA, Schaff HV, et al Identifying patients at particular risk of injury during repeat sternotomy: analysis of 2555 cardiac reoperations. J Thorac Cardiovasc Surg. 2010;140: 1028-35.

4. Kamdar F, John R, Eckman P, Colvin-Adams M, Shumway SJ, Liao K Postcardiac transplant survival in the current era in patients receiving continuous-flow left ventricular assist devices. J Thorac Cardiovasc Surg. 2013; 145:575-81.

5. Cheung A, Lamarche Y, Kaan A, Munt B, Doyle A, Bashir J, et al. Off-pump implantation of the HeartWare HVAD left ventricular assist device through minimally invasive incisions. Ann Thorac Surg. 2011;91:1294-6.

\title{
Left atrial pressure monitoring in patients with a HeartMate II device using a Codman Microsensor
}

\author{
Igor Gosev, MD, Leacche Marzia, MD, Robert C. Neely, MD, and Gregory S. Couper, MD, Boston, Mass
}

Ventricular assist devices have become an important element for the treatment of advanced heart failure. ${ }^{1}$ Since 2006, more than 6000 mechanical assist devices have been implanted in patients in the United States. ${ }^{2}$ In 2008, the

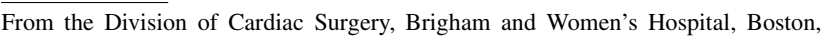
Mass.

Disclosures: Authors have nothing to disclose with regard to commercial support. Received for publication Aug 8, 2013; revisions received Nov 29, 2013; accepted for publication Dec 10, 2013; available ahead of print Jan 10, 2014.

Address for reprints: Igor Gosev, MD, Division of Cardiac Surgery, Brigham and Women's

Hospital, 75 Frances St, Boston, MA 02115 (E-mail: igosev@ partners.org).

J Thorac Cardiovasc Surg 2014;147:1425-7

$0022-5223 / \$ 36.00$

Copyright (c) 2014 by The American Association for Thoracic Surgery

http://dx.doi.org/10.1016/j.jtcvs.2013.12.003
}

second-generation axial flow HeartMate II (Thoratec Corp, Pleasanton, Calif) pump was approved by the Food and Drug Administration as a bridge to transplant therapy

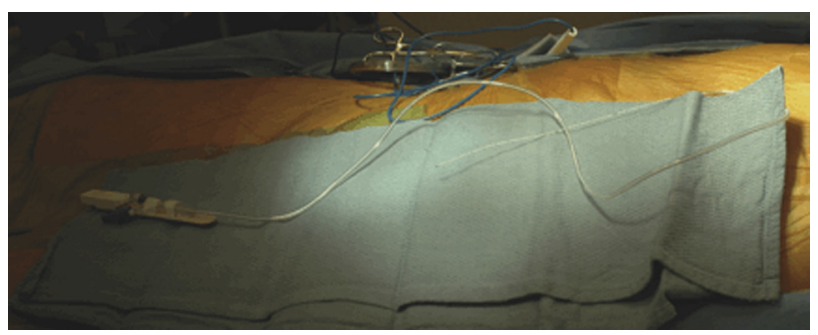

FIGURE 1. Assembled left atrial line. 